\title{
SEMANTIC ANALYSIS OF THE FIRST CITIES FROM A DECONSTRUCTION PERSPECTIVE
}

\author{
Mojtaba Valibeigi, Faezeh Ashuri \\ Buein Zahra Technical University \\ Imam Khomeini Blvd, Buein Zahra, Qazvin, Iran
}

*Corresponding author: mojtaba.valibeigi@bzte.ac.ir

\begin{abstract}
Introduction: Deconstruction is looking for any meaning, semantics and concepts and then shows how all of them seem to lead to chaos, and are always on the border of meaning duality. Purpose of the study: The study is aimed to investigate urban identity from a deconstruction perspective. Since two important bases of deconstruction are text and meaning and their relationships, we chose the first cities on a symbolic level as a text and tried to analyze their meanings. Methods: The study used a deductive content analysis in three steps including preparation, organization and final report or conclusion. In the first step, we argued deconstruction philosophy based on Derrida's views accordingly. Then we determined some common semantic features of the first cities. Finally, we presented some conclusions based on a semantic interpretation of the first cities' identity. Results: It seems that all cities as texts tend to provoke a special imaginary meaning, while simultaneously promoting and emphasizing the opposite meaning of what they want to show.
\end{abstract}

\section{Keywords}

Deconstruction, text, meaning, urban semantics, the first cities.

\section{Introduction}

Expressions are an act of recognizing or displaying a particular concept. The purpose of each expression is to communicate something. Sometimes notes, lines, shapes, colors, and perhaps all the constituent elements of a building or a city can be a kind of an expression, a sign giving a special meaning. Since people live in a built environment, they begin to assign meaning and create signs for objects, with each one expressing a specific concept. With different expressions, we try to show different concepts (Anderson and de Saussure, 2018; Coward and Ellis, 2016; Stoltz, 2019). Symbolic codes create the so-called Kevin Lynch legibility and readability by making marks in objects, behaviors, and mentalities (Lynch, 1960, 1995).

Urban semiotics is based on a kind of a semantic load on all urban phenomena that extensively uses the process of differentiation. The differentiation is considered as a factor for identification and recognition and as a value that is located among many urban symbols (Almeida, 2018). Urban semiotics relate the fusion of ideology and power structures to human urban space. The analysis consists in the investigation of public imagination and meaning code articulated with space (Gottdiener and Lagopoulos, 1986; Pipkin et al., 1983). Consequently, the space is known when the symbolic meaning and its complex impact on human behavior have been recognized (Harvey, 1970, 2009).

Different meanings can be shown through spatial forms. Just as a text contains a message, the spatial forms of a city, like the letters of a text, can be considered to have a specific meaning (Gualberto and Kress, 2019; Leone, 2019; Stojiljković and Ristić Trajković, 2018). If the city contains signs and symbols, then the meaning of these symbols can be understood by people; we should seek to understand the meaning that people receive from their built environment (Knox, 1984).

As a result, traditionally in urban semantics, urban signs and symbols have a special meaning and try to show that special meaning to the audience. By recognizing the meaning of these symbols and signs and their differences, the researcher can reach a general meaning of the urban identity that a city wants to narrate. The aim of this study is to criticize this traditional urban semantics approach from a deconstructionist perspective; and in this respect to examine the urban identity of the first cities. Based on this idea, the research consists of four parts as follows: first, the method and steps of this research are described; then, the philosophy of deconstruction is studied based on Derrida's views; in the third part, the common symbols and symbols of the first cities are examined; finally, the concepts and symbols of the first cities are critically deconstructed.

\section{Research method}

This research used a qualitative content analysis method in the semantic reading of the city's identity. In analyzing the qualitative content of this research, by examining the concepts, terms and connections between these concepts, we attempted to deduce and reveal the hidden patterns in written documents and observations. Using deductive logic, we did it in three steps of 
preparation, organization and reporting. In the preparation step, the deconstructive perspective on text and symbol analysis is examined first. In the organizational step, the elements, symbols, signs and common concepts of the first cities are brought together, and in the final step, the interpretation and report of these symbols of the first cities are presented based on the deconstructionist perspective.

Content in content analysis refers to any document that indicates the relationship between human beings. Therefore, the paintings engraved in caves, music, books, articles, manuscripts, postcards, movies, etc., we call content. Accordingly, content analysis is a method of analyzing qualitative studies by which data is summarized, described, and interpreted. When researchers intend to test or verify the validity of a theory, model, or hypothesis, they use a deductive content analysis (Anandarajan et al., 2019; Kyngäs and Kaakinen, 2020). Accordingly, since this study seeks to investigate the validity of deconstruction theory in the field of urban semantics, we used the method of deductive content analysis and chose the first cities as a text.

\section{Results}

\section{A. Step 1: basic concepts in deconstruction}

Hans Gadamer argued the idea that there is a fundamental unity between thought, language, and the universe, and that it is within the language that our present horizon is constructed and addressed. According to poststructuralists, the meaning of any identity can be achieved through language. The focus of this movement is on the role of language in poststructuralist theories. It can be clearly seen in the views of Jacques Derrida, Michel Foucault, Roland Barthes (Aitken and Valentine, 2015; Harari, 2019; Parkes, 2012; Poster, 2019). The term deconstruction was coined by French philosopher Jacques Derrida (1930-2004). Deconstruction acts to illuminate another meaningful layer in a text. The underlying meaning that hides itself, however, is there. The text is multimeaningful in this respect and does not have a specific meaning, and as much as it refers to a particular meaning, it also refers to its reversal (Culler, 2007; McQuillan, 2017). Each text is a complex combination of symbols and signs; we can never know what these symbols mean. A symbol wants to point to something, and there is a difference between that symbol and that concept. It is this difference and distance that determine the meaning. But since it is never possible to say with certainty what the symbol refers to, the meaning is uncertain (Sallis, 1987). Accordingly, in deconstructing the critique, Derrida's deconstruction view claims that the true meaning of the text is unattainable. Accordingly, each text is a complex combination of symbols and signs that, when searching for its meaning, shows conflicting meanings simultaneously. These contradictory meanings are also due to the fact that no word has a completely independent meaning and concept, and it finds meaning only when we understand its opposite meaning and with the help of that opposite, it acquires the meaning. Accordingly, Derrida argues that the meaning is not directly present in the symbol, sign, because the meaning of a word and symbol is what that sign is not, and because each word is constructed by its difference from other words. The meaning is never fully present in the word itself; it is rather made up of differences with other words, in other words, the meaning is "delayed", and as much as its meaning is due to itself, it is also due to its opposite meaning, by which it has found the meaning (Michelfelder and Palmer, 1989; Sallis, 1987; Wolfreys, 1998).

There is no escape from contradiction according to Derrida. Deconstruction considers how philosophical texts, when setting the definition as the starting point, do not pay attention to this fact that all these behaviors which led to definition, have an inner order, the order in which everything has been defined due to what was not before it (Evans, 1991; Wood and Bernasconi, 1988). In a text with such a broken foundation, the meaning, both the superior and the opposite one, disappears. Accordingly, the text is turned to multi-meanings; and because of countless interpretations, the final meaning is lost (Derrida and Bennington, 1993; Freshwater and Rolfe, 2004; Payne, 1993; Wood, 1992; Wolfreys, 1998). Derrida showed that all texts are based on dual orders, such as existence/non-existence, man/woman, where the first member of each pair is considered as the meaning and has a preference. In all those schools of thought, there is a hypothetical vantage core or an Archimedean point. These hypothetical vantage cores came in view of deconstruction, as being useless and non-hierarchical of that was previously discovered, and what was considered constant and logical became unreasonable and void, with the interpretation itself containing many misconceptions (Naas, 2003; Wolfreys, 1998).

\section{B. Step 2: the first cities}

The city as the first form of civilization and the center of holiness, power and wealth always possessed an ideal and sacred meaning. It tended to portray its socio-philosophical aspirations towards the future and its destination that led to the emergence of different ideals (Morris, 2013; Nas, 2011; Seasoltz, 2005). Several studies showed the definitive impact of the subject of the worldview on the genesis of the first cities (Ghirshman, 1961; Rohl, 1999). A city acts as a physical crystallization of the society that shaped it and tries to show their valuable concepts. Valued and sacred signs in the cities, naturally, are guaranteed and continuous mechanisms that can re-generate or, vice versa, eliminate and degrade semantic loads over time. The first cities were basically created as symbolic centers of ceremonies (see Fig.1). Thus, the city is a symbol of the world and it has the power to organize and regulate wider areas (Bryce, 2009; Potts, 2006; Osborne, 2014).

The number of the cities that are called "the center of the world", "the heart of the world", "the axis of the world", etc., is interesting. In mythology, most cultures come across a concept called "the world axis". This centrality is actually reflected in the culture itself. In other words, cultures have always considered themselves the center of the universe, and they have imagined that they have the closest relationship with the Lord and Creator of the universe because of this centrality. In these cultures, the geographical position was usually a focal point, therefore it was sanctified (Clark, 2013; Hibbert, 1987; Morris, 2013). 


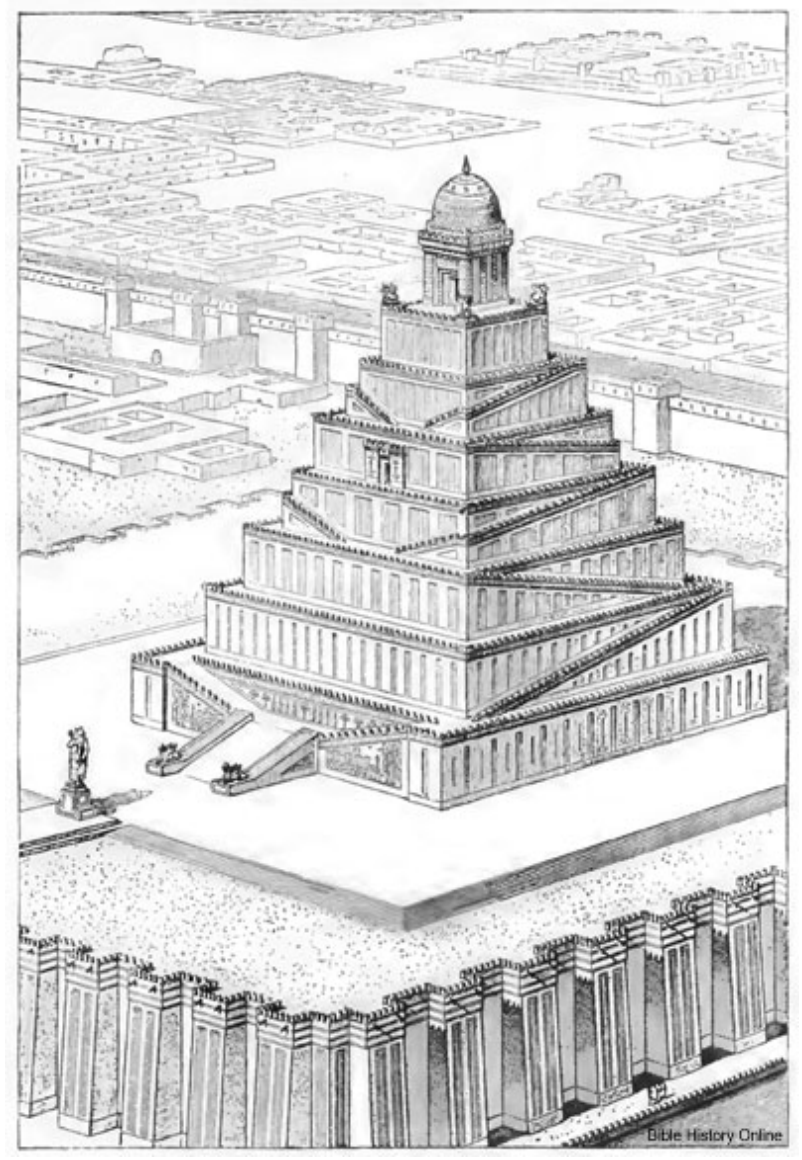

Figure 1. The first cities as symbolic centers of ceremonies. Drawing of a Ziggurat with seven stages. Source: Bible History Online

According to a semantic study of the elements, concepts and symbols of the first cities, we see common concepts in most of them. There are symbols trying to express specific meanings to the audience, which can be considered the basic and underlying principles of the most of urban symbols made in the first cities. These meanings are: the center of the world defying a subordinate position; a manifestation of perfection and divine order in contrast to the disorder of the outer world; eternal presence and stability versus instability, mortality.

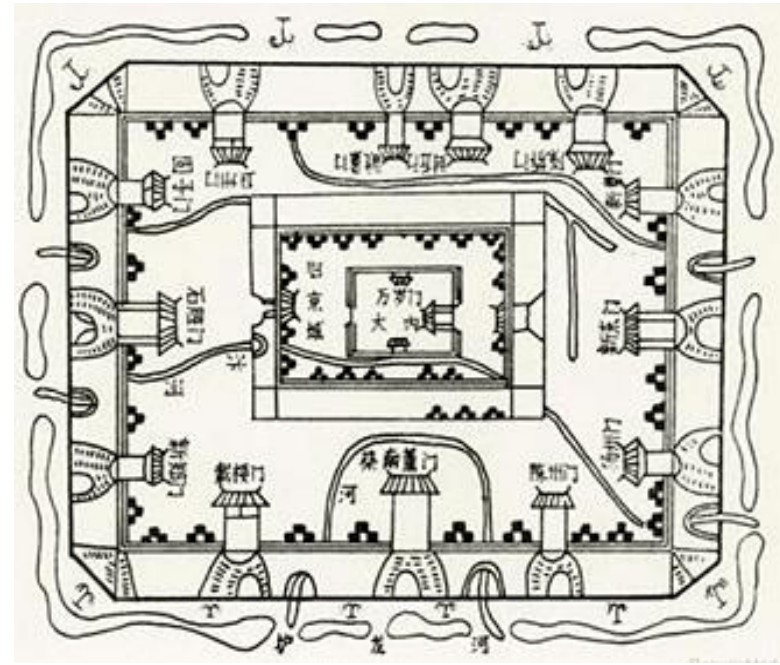

Figure 2. Chinese cartographic view of the city. Source: N.S. Steinhardt, 1999
We further investigated the concepts in Chinese first cities.

\section{The first cities of China}

Ancient Chinese cities have been described as a symbol of the order of the universe. The texture of the gates, the fences, the order of the streets, the location of the city center and its nature have all been aspects of astrobiology. In this view, sacred things are real and only sacred things are safe. Biological complexes and buildings are similar to their celestial specimens and must be consecrated before they can become habitable. This sanctification was made possible by the connection between heaven, earth, and the underworld.

In the cosmological landscape, the first cities of China are a vehicle designed to capture and redistribute $\mathrm{Qi}$, the divine breath, the power that animates human affairs and carries with it the mandate of heaven. It is embodied in the magic square, Feng.

The main features of such urban models are based on centralism, with the emphasis on the main world, focalism and the existence of a fence. In such first city models, the fence is seen as a sacred place rather than playing a defensive role (Morris, 2013).
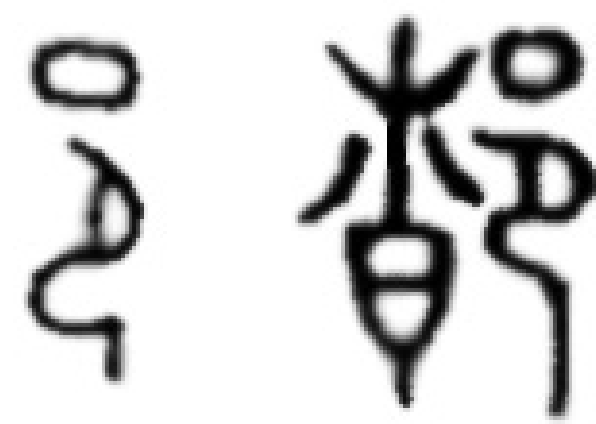

Figure 3. Sample of the Shang Dynasty ideograph for the first cities of China. Source: chaz.org

For example, in Fig. 3, we have the Shang Dynasty ideograph for "city". It is a kneeling person beneath a city wall. The kneeling person signifies submission to the state and the burden of citizenship. It recognizes that a city is most essential for the people who live within its walls. The city wall is not simply a matter of defense. Cosmologically, it creates a divine vessel that centers God's rule on earth and projects the power of the state. Hence, traditional Chinese cities and the governments they nurture are primarily sacred in their fundamental nature. On the right, the ideograph for "capital" adds the symbol for a granary, which evolves into the symbol for a market.

A Chinese city was a means of capturing cosmic forces and distributing them throughout the earth, and to identify a point as a city, the Chinese considered the following criteria: an altar to the god of soil, fences, and a temple for ancestors. The city, which symbolizes the acquisition of the divine forces and the safe place from the chaotic outer world, was separated from it by fences. The city is a sign of eternity and constant presence that manifests itself in the temple of the ancestors. A Chinese city was 
a solution by which the presence and immortality could forget inexistence and nullity; it assumed the form of denial and overcoming of death that declares its presence in the temple of the ancestors. The state of the city, as a place to obtain the divine forces, conveys a state of stability and resilience, and through its sacredness, creates a feeling of security for the audience. The city becomes a place where God and the earth come together and open their gates to the corners of the world, giving it a sacred state (see Fig. 4). In fact, all symbols, sings and concepts of the city are plays, conventions, and solutions for men and power structures to show their eternal presence.

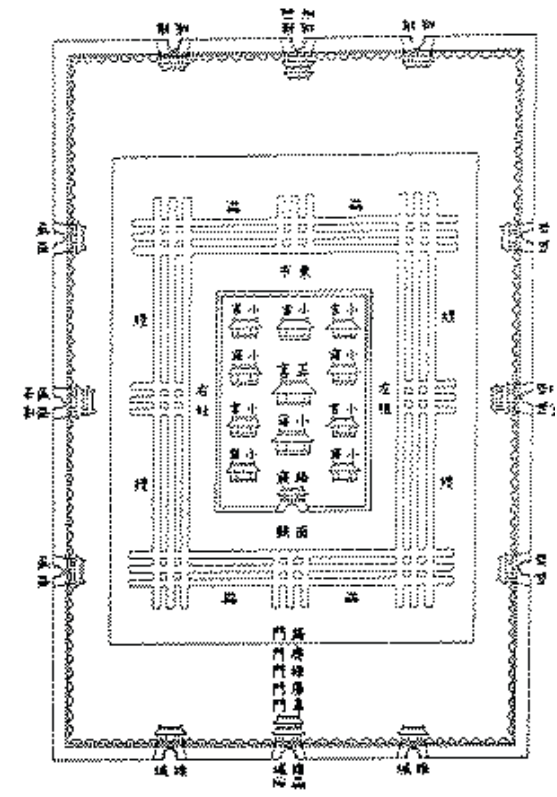

Figure 4. Structure of ancient Chinese cities, China. City, Han ${ }^{1}$. Source: Chaz.org

\section{Conclusion}

The third step or conclusion in content analysis is the result of the analysis of the previous two steps. It has already been mentioned that deconstruction states that since all concepts are relative, no exact meaning can be considered for any symbol. Moreover, when we look at symbols and signs from a structural point of view, we see that in addition to the literal meaning that we assume for symbols, the opposite meaning is quite conceivable for them as well. Each symbol has two meanings: the literal meaning and another meaning that is in conflict with the literal one, which is due to their relative nature. The second step was to answer the question, what are the common symbols and signs of the first cities? What did the first cities tend to mean semantically? And as mentioned, we see common concepts among most of the first cities: centrality and focalism in the world; manifestation of perfection and divine order; eternal presence, stability and order.

From the viewpoint of deconstruction, the constructed form known as the city hides its semantic foundations, which it claims in order to obtain eternal presence and identity, and in the meantime, the concept of the city is defined in terms of its superior dimensions. And it tries to implicitly reject the concepts against them, namely instability, nonexistence, absence, by showing the concepts of stability, existence, presence, and so on. The city implicitly tries to cover up the facts and create what it lacks through its symbols. Therefore, it forms symbols that represent safety, permanence, and perpetual presence. In other words, the creation of such symbols is an unconscious reaction to the lack of such concepts in the city, and an attempt to overcome the fear of instability, insecurity, and death that is felt at all times. The city tries to cover them through its symbols, while this game of denial through symbols causes both these opposing meanings of existence and nonexistence to be produced and reproduced at any moment, consciously or unconsciously. Behind their literal meaning, such symbols produce and reflect fears, shortages, and the lack of a permanent presence that history bears witness to. Then, each symbol puts its semantic roots in its contradictory meanings in addition to its literal meaning, and urban symbols become multifaceted. The identity that the first cities sought to show through their symbolism was a testament to the lack of such an identity, and that is why they tried to create it through symbolism, and that is why all those ceremonies and symbols were required. Symbols, in turn, indicate a lack of such an identity. The idea of purity and perfection and self-discipline becomes the source of impurity, imperfection and disorder. The notion is that perfection always has "imperfection" in it; it is as if perfection has always taken refuge in the flaw. Such symbolism forms when analyzed by deconstruction, what seemed perfection, acknowledge their imperfection. In fact, within each city, there are two types of cities. There is the first city, formed by the authority of that time, and, thus, understood and interpreted on this basis. Its logic and truth can be found; everything in it was reduced to the double contradictions like persistence/instability, real/ unreal. But it also presents the second city, which is freed from the double contradictions; the logic and truth cannot be found in it, and with the roots devoid of their symbolic meaning, it loses any meaning at all. And so, the first city is the symbol for this second city. This latter aspect of urban identity is what deconstruction strives to show.

\footnotetext{
1 The Kaogongji (Kao Gong Ji) was an official guide that set forth standards to be followed in various crafts and trades, including those for the structure of a provincial-level capital for a prince. It dates to the late Spring and Autumn period (about $500 \mathrm{BC}$ ), but the oldest surviving copy dates to 1235 AD. According to the Kaogongji: "When the builder constructs the capital, the city should be a fang (a four-sided orthogonal shape) nine li on each side with three gates each. Within the city are nine longitudinal and nine latitudinal streets, each of them 9 carriages wide. On the left (i.e. east) is the Ancestral Temple, on the right (west) are the Altars of Soil and Grain, in front is the Hall of Audience and behind the markets".

The Kaogongji, which disrupts movement within the city by having a large, walled administrative district in the center, was used by early states particularly in southern China and owes much of its spatial arrangement to the field well system, which places activities that directly support the ruler in the center of a three-by-three grid (source: Chaz.org).
} 


\section{References}

Aitken, S. C. and Valentine, G. (2015). Approaches to human geography: Philosophies, theories, people and practices. $2^{\text {nd }}$ edtition. New York: Sage, $456 \mathrm{p}$.

Almeida, R. N. (2018). From heritage interpretation to cultural systems: outline of an urban semiotics of culture. Book of Abstracts of the Third International Conference of Young Urban Researchers, p. 78.

Anandarajan, M., Hill, C. and Nolan, T. (2019). The fundamentals of content analysis. In: Practical Text Analytics. Advances in Analytics and Data Science, 2, pp. 15-25. DOI: 10.1007/978-3-319-95663-3_2.

Anderson, S. R. and de Saussure, L. (eds) (2018). René de Saussure and the theory of word formation. Berlin: Language Science Press, $241 \mathrm{p}$.

Bryce, T. (2009). The Routledge handbook of the peoples and places of ancient Western Asia: The Near East from the early Bronze Age to the fall of the Persian Empire. London: Routledge, 944 p.

Clark, P. (ed.) (2013). The Oxford handbook of cities in world history. Oxford: Oxford University Press, 912 p.

Coward, R. and Ellis, J. (2016). Language and materialism: developments in semiology and the theory of the subject. London: Routledge, $165 \mathrm{p}$.

Culler, J. (2007). On deconstruction: Theory and criticism after structuralism. Ithaca: Cornell University Press, 317 p.

Derrida, J. and Bennington, J. (1993). Jacques Derrida. Translated by G. Bennington. Chicago: University of Chicago Press, 417 p.

Evans, J. C. (1991). Strategies of deconstruction: Derrida and the myth of the voice. Minneapolis: University of Minnesota Press, $205 \mathrm{p}$.

Freshwater, D. and Rolfe, G. (2004). Deconstructing evidence-based practice. Hove: Psychology Press, 216 p.

Ghirshman, R. (1961). The Ziggurat of Tchoga-Zanbil. Scientific American, 204 (1), pp. 68-77.

Gottdiener, M. and Lagopoulos, A. P. (1986). The city and the sign: An introduction to urban semiotics. New York: Columbia University Press, 344 p.

Gualberto, C. and Kress, G. (2019). Social semiotics. In: Hobbs, R., Mihailidis, P. (eds). The International Encyclopedia of Media Literacy. New York: Wiley-Blackwell. DOI: 10.1002/9781118978238.ieml0226.

Harari, J. V. (2019). Textual strategies: Perspectives in post-structuralist criticism. Ithaca: Cornell University Press, 464 p.

Harvey, D. (1970). Social processes and spatial form: an analysis of the conceptual problems of urban planning. Papers in Regional Science, 25 (1), pp. 47-69. DOI: 10.1111/j.1435-5597.1970.tb01477.x.

Harvey, D. (2009). Social justice and the city. Athens: University of Georgia Press, 368 p.

Hibbert, C. (1987). Cities and civilizations. London: Weidenfeld and Nicolson, 256 p.

Knox, P. L. (1984). Symbolism, styles and settings: the built environment and the imperatives of urbanized capitalism. Architecture and Behaviour, 2 (2), pp. 107-122.

Kyngäs, H. and Kaakinen, P. (2020). Deductive content analysis. In: Kyngäs, H., Mikkonen, K., Kääriäinen, M. (eds). The Application of Content Analysis in Nursing Science Research. Cham: Springer, 23-30. DOI: 10.1007/978-3-030-30199-6_3.

Lagasse, P., Goldman, L., Hobson, A., Norton, S. R. (eds) (2003). The Columbia encyclopedia. $6^{\text {th }}$ edition. New York: Columbia University Press, 3200 p.

Leone, M. (2019). City of nostalgia: the semiotics of urban retrotopias. Chinese Semiotic Studies, 15 (1), pp. 77-94. DOI: 10.1515/ css-2019-0005.

Lynch, K. (1960). The image of the city. Cambridge, London: MIT Press, 194 p. 
Lynch, K. (1995). City sense and city design: writings and projects of Kevin Lynch. Cambridge: MIT Press, 866 p.

McQuillan, M. (ed.) (2017). Deconstruction: A reader. New York: Routledge, 596 p.

Michelfelder, D. P. and Palmer, R. E. (eds) (1989). Dialogue and deconstruction: the Gadamer-Derrida encounter. Albany: State University of New York Press, 352 p.

Morris, A. E. J. (2013). History of urban form before the industrial revolution. $3^{\text {rd }}$ edition. London, New York: Routledge, $456 \mathrm{p}$.

Naas, M. (2003). Taking on the tradition: Jacques Derrida and the legacies of deconstruction. Stanford: Stanford University Press, $211 \mathrm{p}$.

Nas, P. J. M. (2011). Cities full of symbols: a theory of urban space and culture. Leiden: Leiden University Press, $303 \mathrm{p}$.

Osborne, J. F. (ed.) (2014). Approaching monumentality in archaeology. Albany: State University of New York Press, 480 p.

Parkes, R. J. (2012). What is poststructuralism. Maysfield: Academic Bytes, 48 p.

Payne, M. (1993). Reading theory: an introduction to Lacan, Derrida and Kristeva. Oxford: Wiley-Blackwell, 264 p.

Pipkin, J. S., La Gory, M. E. and Blau, J. R. (1983). Remaking the city. Albany: State University of New York Press, 409 p.

Poster, M. (2019). Critical theory and poststructuralism: In search of a context. Ithaca, London: Cornell University Press, 200 p.

Potts, D. T. (2006). Elamites and kassites in the Persian Gulf. Journal of Near Eastern Studies, 65 (2), pp. 111-119.

Rohl, D. M. (1999). Legend: the genesis of civilization (a test of time). Vol. 2. London: Arrow, 540 p.

Sallis, J. (ed.) (1987). Deconstruction and philosophy: The texts of Jacques Derrida. Chicago: University of Chicago Press, 207 p.

Seasoltz, R. K. (2005). A sense of the sacred: Theological foundations of Christian architecture and art. Edinburgh: A\&C Black, $394 \mathrm{p}$.

Steinhardt, N.S. (1999). Chinese imperial city planning. Honolulu: University of Hawaii Press, 228 p.

Stojiljković, D. and Ristić Trajković, J. (2018). Semiotics and urban culture: architectural projections of structuralism in a socialist context. Social Semiotics, 28 (3), pp. 330-348. DOI: 10.1080/10350330.2017.1300084.

Stoltz, D.S. (2019). Becoming a dominant misinterpreted source: The case of Ferdinand de Saussure in cultural sociology. Journal of Classical Sociology. DOI: 10.1177/1468795X19896056.

Wolfreys, J. (1998). Deconstruction. Derrida. London: Macmillan, 256 p.

Wood, D. (1992). Derrida: a critical reader. Oxford: Wiley-Blackwell, 297 p.

Wood, D. and Bernasconi, R. (1988). Derrida and Différance. Evanston: Northwestern University Press, 98 p. 